\title{
Crafting usable knowledge for sustainable development
}

\author{
William C. Clark ${ }^{a, 1}$, Lorrae van Kerkhoff ${ }^{b}$, Louis Lebel ${ }^{c}$, and Gilberto C. Gallopin ${ }^{d}$ \\ Edited by B. L. Turner, Arizona State University, Tempe, AZ, and approved March 18, 2016 (received for review January 27, 2016)
}

This paper distills core lessons about how researchers (scientists, engineers, planners, etc.) interested in promoting sustainable development can increase the likelihood of producing usable knowledge. We draw the lessons from both practical experience in diverse contexts around the world and from scholarly advances in understanding the relationships between science and society. Many of these lessons will be familiar to those with experience in crafting knowledge to support action for sustainable development. However, few are included in the formal training of researchers. As a result, when scientists and engineers first venture out of the laboratory or library with the goal of linking their knowledge with action, the outcome has often been ineffectiveness and disillusionment. We therefore articulate here a core set of lessons that we believe should become part of the basic training for researchers interested in crafting usable knowledge for sustainable development. These lessons entail at least four things researchers should know, and four things they should do. The knowing lessons involve understanding the coproduction relationships through which knowledge making and decision making shape one another in social-environmental systems. We highlight the lessons that emerge from examining those coproduction relationships through the ICAP lens, viewing them from the perspectives of Innovation systems, Complex systems, Adaptive systems, and Political systems. The doing lessons involve improving the capacity of the research community to put its understanding of coproduction into practice. We highlight steps through which researchers can help build capacities for stakeholder collaboration, social learning, knowledge governance, and researcher training.

sustainable development | knowledge systems | capacity | coproduction | science-policy interface

This paper seeks to promote better mobilization of knowledge for the pursuit of sustainable development. Our starting point is the original vision of sustainability (we use "sustainability" and "sustainable development" interchangeably throughout this paper) set forth by the World Commission on Environment and Development in 1987 and recently reaffirmed and refined by the United Nations (UN) General Assembly's formal adoption of The 2030 Agenda for Sustainable Development. Here we follow recent scholarship $(1,2)$ in encompassing the multiple UN goals under a broader conceptualization that sees sustainable development as the promotion of inclusive human well-being; this is to say, well-being that is shared equitably within and across generations and is built on the enlightened and integrated stewardship of the planet's environmental, economic, and social assets.
Great improvements have taken place in many people's well-being over recent generations. However, contemporary development is not sustainable development. It leaves too many of today's people behind (3). Also, it achieves today's increasingly inequitable gains by degrading many of the essential assets on which the prospects for tomorrow's prosperity depend. Promoting a transition toward more sustainable development paths is an urgent task that will require unprecedented contributions from political leaders, business entrepreneurs, and civil society actors working together across scales. However, it will also require mobilizing more and better knowledge of ways to secure and sustain inclusive improvements in human well-being. Much of the needed knowledge already exists, but new discoveries, inventions, and practices are also needed.

${ }^{a}$ Kennedy School of Government, Harvard University, Cambridge, MA 02138; ${ }^{b}$ Fenner School of Environment and Society, Australian National University College of Medicine, Biology and Environment, The Australian National University, Canberra, ACT 2600, Australia; ' Unit for Social and Environmental Research, Faculty of Social Sciences, Chiang Mai University, Chiang Mai 50200, Thailand; and Independent Scholar, Tte. Gral. J.D. Peron, Buenos Aires 1040, Argentina

This paper results from the Arthur M. Sackler Colloquium of the National Academy of Sciences, "Linking Knowledge with Action for Sustainable Development" held April 3-4, 2008, at the National Academy of Sciences in Washington, DC. The complete program and audio files of most presentations are available on the NAS website at: www.nasonline.org/SACKLER_sustainable_development.

Author contributions: W.C.C., L.v.K., L.L., and G.C.G. designed research, performed research, and wrote the paper.

The authors declare no conflict of interest.

This article is a PNAS Direct Submission.

${ }^{1}$ To whom correspondence should be addressed. Email: william_clark@harvard.edu. 
What are the prospects for successful mobilization of knowledge to promote sustainable development? Much has clearly been accomplished. However, too much potentially valuable knowledge produced by committed researchers languishes in libraries, unused by society; and too many of society's greatest needs for new knowledge remain relatively unexplored by researchers. A transition toward sustainability thus requires not just more knowledge, but more usable knowledge.

A great deal has been learned in recent years about the nature and production of usable knowledge $(4,5)$. This is reflected not only in a growing body of case studies on relationships between science and society but also in flourishing fields of relevant theory building, replete with the requisite jargon and specialist debates. We have sought through our own work to make both empirical and theoretical contributions to this emerging body of scholarship and to apply it in advancing sustainable development on the ground. In pursuing those applications, however, we found that the very success of science and society studies as a field of fundamental scholarship has tended to make its practical implications increasingly inaccessible to many of the researchers who might use it in their struggles to produce more usable knowledge. Our goal in this paper is therefore not to enrich fundamental understanding of science-society relationships, but rather to distill some of what we believe to be the field's most important practical implications for sustainability-related research. In particular, we present here our response to two pragmatic questions: (i) what should researchers know about the nature of usable knowledge and the barriers and opportunities for producing it; and (ii) what should they do to translate what they know into action?

\section{What Should Researchers Know About Usable Knowledge?}

Researchers working on sustainable development generally acknowledge that they are seeking to understand the dynamics of coupled "social-environmental systems" (SESs; we use this term to encompass work describing itself as focused on socio-ecological systems, social-ecological systems, and coupled human-environment systems), in which the social (human populations, economies, technologies, institutions, etc.) interacts with the environmental (climate, ecosystems, biogeochemical cycles, etc.) at multiple scales (6-8). Less widely appreciated is that knowledge-making and decision-making in such systems are continually reshaping one another in what have been called relationships of "coproduction" $(9,10)$. Consider, for example, how the growing scientific evidence for transboundary movement of pollutants in the 1980s helped to launch whole new forms of international environmental treaties. At the same time, however, that drive for global rules undermined attention to the local knowledge that was necessary for implementing the global rules effectively in particular contexts. Another example is how hydropower researchers' preference for improving large dams and turbines rather than smallscale, in-stream generators resonated with governments' preference for centralized planning and decision-making rather than the empowerment of local communities. Such coproduction relationships have profound implications for researchers who are striving to craft usable knowledge for sustainable development. We have found that those implications can be illuminated by viewing coproduction in SESs through the "ICAP" lens: seeing them as Innovation systems, Complex systems, Adaptive systems, and Political systems (Fig. 1).

Innovation Systems. This first ICAP perspective highlights that researchers' new discoveries, inventions, or insights become usable knowledge only through integration within larger innovation systems. A copious literature on such systems addresses the factors shaping how new knowledge is "conceived, developed, codified, and deployed" $(11,12)$. For our purposes, it implies that to produce usable knowledge for sustainable development, researchers need to (i) listen to the potential users who they hope will act upon their discoveries, adjusting their agendas to reflect those users' needs rather than the enthusiasms of academia or funders; (ii) integrate their work on discovery and invention with complementary innovation processes involving adjustment to fit local contexts, field testing, scale-up, and retirement; and (iii) realize that new knowledge is more likely to become useable knowledge when it is shaped to "fit" within, and thus draw utility from, the system of existing ideas, technologies, and governing institutions. Sustainable development also needs radical new knowledge that challenges existing ideas, technologies, and practices. However, such potentially transformative knowledge will still need to find connections into existing innovation systems and will thus depend on actor coalitions pushing the system to adopt and use it $(13,14)$.

The importance of seeing the challenge of crafting usable knowledge in terms of whole innovation systems, rather than discovery or invention alone, is illustrated by the history of the first green revolution in agriculture (henceforth "GR1"; 1966-1985) (15). GR1 was launched with the goal of inventing and making publically available high yielding crop varieties that could alleviate the risk of hunger in the developing world. Its basic strategy was to do the inventing by mobilizing scientific talent from around the world in newly formed global research centers and then relying on public and private sector actors at the national level to do the essential work of adaptation to local conditions, field testing, and dissemination. By many measures, GR1 was a success. On the other hand, the initial selection of crops on which to focus was

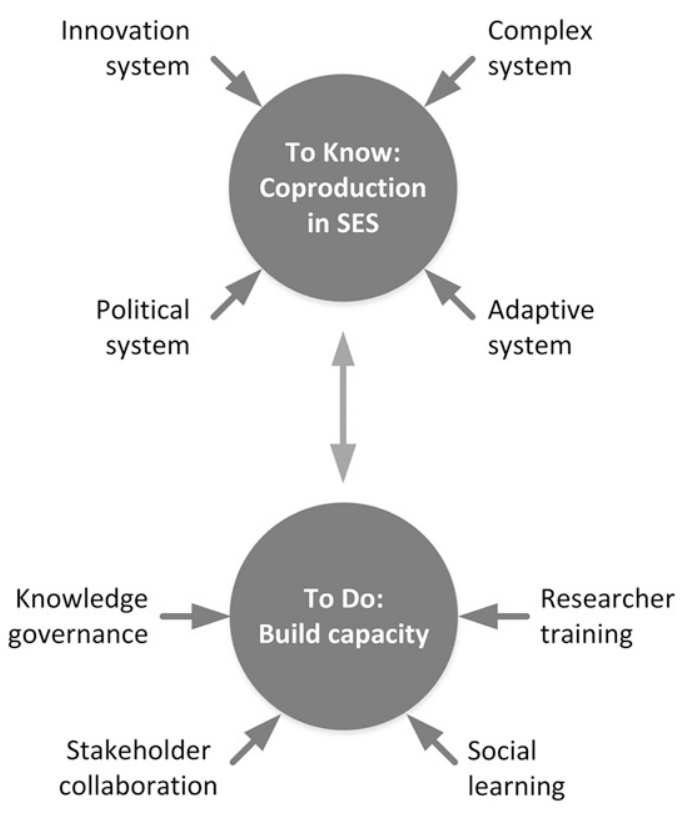

Fig. 1. A framework for crafting usable knowledge for sustainable development. The coproduction relations of social-environmental systems are understood through lenses seeing them as innovation, complex, adaptive, and political systems (knowing). Capacities to mobilize this understanding for creating usable knowledge are needed in the realms of stakeholder collaboration, social learning, knowledge governance, and researcher training (doing). 
strongly influenced by what crops had already been studied in the developed world rather than by the needs of farmers in the developing world. As a result, many important crops-especially for Africa-were neglected. Even for those crops that were selected, the research emphasis was on developing varieties that would result in higher yields under "favorable conditions" of ample water from rain or irrigation, on top of access to fertilizers and pesticides. Places that could not meet such conditions generally failed to benefit from GR1. Since the mid-2000s, these multiple shortcomings have been addressed in a second "evergreen" revolution, one more focused on the needs of the least well off farmers, more attentive to environmental and health effects of new crop varieties and practices, and more committed to nurturing local capacity for fitting new varieties to specific social-environmental contexts (16). That revolution in innovation systems for food production is ongoing with some clear success. However, the ultimate outcome remains to be seen.

Innovation systems analysis has shown that efforts to craft usable knowledge have been constrained by models of researcher-driven, one-directional "technology transfer." Reformers have called for and implemented more collaborative, iterative, and interactive models of innovation that acknowledge the importance of coproduction relationships between knowledge-making and decision-making. The systemic perspective emphasizes that for success in crafting usable knowledge, researchers must understand the need to work together not only with ultimate users and decision makers, but also with a host of other actors involved in performing the multiple tasks of a well-functioning innovation system: funders, entrepreneurs, field evaluators, etc.

Complex Systems. Our second ICAP perspective suggests that researchers seeking to produce usable knowledge for sustainable development should know that the SESs they seek to influence are profoundly complex systems. The study of such systems has generated a substantial literature about how collective behaviors of a relevant "whole" (sand dunes, a human body, an SES) emerge not only from the properties of its component parts, but also from the interactions among its component parts and between those parts and their surroundings (17). This literature suggests that to produce usable knowledge for sustainable development, researchers should know that (i) you can't just do one thing (i.e., your discoveries, inventions, and interventions will have multiple impacts at multiple scales and not just the one you intended); (ii) those impacts will almost always be context dependent, rendering quixotic the quest for "panaceas" that can be applied universally (18); and (iii) those impacts may involve abrupt or irreversible changes to the system, limiting the efficacy of traditional trial and error approaches.

A striking example of the challenges that the complex system character of SESs pose for efforts to craft usable knowledge is provided by recent efforts to promote biofuels as a sustainable alternative to fossil fuels (19-21). The basic concept, backed by early experience in Brazil, made biofuels seem to many a perfect case for moving knowledge into action for sustainability: the plants would capture sunlight and carbon dioxide and turn it into fuels that could be burned with little or no net release of greenhouse gases. However, although net emissions of greenhouse gases from the use of sugar cane biofuels produced in Brazil were indeed substantially lower than those of the fossil fuels they replaced, emissions of biofuels produced from heavily fertilized corn in the United States turned out to be higher (i.e., no panaceas). Worse, the biggest impact of promoting corn-based biofuels turned out not to be on greenhouse gas emissions at all, but rather on food prices. The shift of crop land from producing food to producing fuel, combined with droughts and policy errors, resulted in spiking food prices around the world that, in turn, exacerbated political unrest (i.e., multiple impacts). The US biofuel blunder turned out to be difficult to reverse because the system of government subsidies put in place to stimulate adoption developed a strong political constituency of its own to keep the program in place (i.e., irreversibility). Comparable examples abound.

Because SESs are complex systems, it is important for researchers to identify the key variables that determine the potential for sustainable development: armed with such knowledge, society has a "watch list" of possible impacts across the entire SES that can counter tendencies to focus prematurely on a narrow range of planned or expected outcomes. Current progress in sustainability science provides a theoretical foundation for this work, suggesting that any scoping effort should identify key variables relevant to the specific SES of interest from each of five major clusters of capital assets: natural capital, human capital, manufactured capital, social capital, and knowledge capital (22). The scoping effort should also seek to identify potential trends in key boundary conditions (environmental and social) that are beyond the control of the SES of interest, but could significantly affect the potential utility of new knowledge there.

Researchers need to realize that exogenous conditions (e.g., climate change, political unrest) may overwhelm local SES dynamics, such that the search for useable knowledge to change those dynamics becomes unrealistic. Finally, researchers should appreciate that even with effective scoping efforts, the nonlinear characteristics of SESs guarantee that the knowledge produced by research will have impacts that researchers didn't intend. It follows that in the face of the complexity of the systems we seek to understand and manage for sustainability, the ultimate requirement for researchers seeking to produce usable knowledge may simply be humility (23).

Adaptive Systems. Our third ICAP perspective suggests that researchers seeking to manage coproduction relationships in SESs should also know that they are intervening in highly adaptive systems. The relevant literature often subsumes the adaptive character of SESs in more general discussions of their behavior as "complex adaptive systems" $(24,25)$. However, systems can be complex without being adaptive. The key features that make even simple systems adaptive involve the added processes of variation and selection. For our purposes here, the ubiquity of such processes in SESs means that researchers hoping to produce usable knowledge for sustainable development should know that (i) novelty is always bubbling up in SESs through natural processes together with human discoveries and inventions; (ii) local conditions, both social and environmental, determine where particular novelties wither away and where some of them prosper and spread (although such conditions often reflect the intersection of multiple higher-order conditions in a particular place); and (iii) the SES dynamics that shape the future will therefore seldom be the same as the ones that have shaped the past.

Humanity's encounter with malaria provides a good example of the challenges for crafting usable knowledge that are posed by the adaptive character of coproduction relationships within SESs $(26,27)$. Malaria is an ancient and deadly disease of humans, caused by parasites that are transmitted via mosquito bites. Throughout history, people have adapted to malaria through the evolution of immunity and development of acquired resistance. Such biological adaptations, however, are restricted to people 
living in places where malaria incidences have historically been high. Newcomers to malarial areas (whether soldiers, traders, tourists, or newborns) lack some or all of the biological adaptations and therefore have historically sickened or died at high rates. Research to protect such biologically vulnerable populations was initially focused on helping a relatively few soldiers and tourists from the rich world, rather than the much more numerous children of the poor world. Researchers nonetheless eventually produced usable knowledge on how to keep mosquitoes and people apart (e.g., with bed nets) and how to kill some of the parasites (with medicines) and mosquitoes (with insecticides). These new discoveries, however, stimulated new adaptations by both pests (that evolved resistance to the poisons and medicines, as well as new feeding habits to mitigate the efficacy of nets) and people (who have appropriated bed nets for a remarkable range of alternative uses). The result is that what was initially usable knowledge no longer does the job, necessitating new efforts to craft knowledge that will be usable (however transiently) for the perpetually changing challenge of malaria control in particular locations around the world. Such continually adapting systems are more the norm than the exception in the SESs we seek to manage in pursuit of sustainable development.

Because SESs are adaptive systems, researchers seeking to craft usable knowledge for sustainability need to see their tasks less in terms of optimality and control and more in terms of flexibility and adaptive management. In other words, researchers should take a significant role in helping society to see its SES interventions reflexively, emphasizing the tentativeness and transience of any new understanding of how the system works. Actions taken in hopes of guiding the system toward sustainability therefore need to be treated as experiments (28). Practically speaking, this means devoting more attention to the design of relevant indicators and monitoring systems, together with ways to make use of such knowledge. At a structural level, it means protecting novelty (conservation) and fostering it (innovation). It also means designing SESs that are "safe-to-fail" (as opposed to futilely striving to make them "fail-safe"), thus allowing them to survive long enough to learn from the blunders and surprises that the future will inevitably entail.

Political Systems. Our final ICAP perspective suggests that researchers seeking to manage coproduction relationships in SESs should take to heart the old adage that "knowledge is power." The creation and deployment of knowledge is therefore likely to be contested by stakeholders in the political systems that are a central feature of SESs where various groups engage in their perennial struggles for "who gets what." The relationships between knowledge and power are central to the growing literature on coproduction $(29,30)$. For our purposes, that literature implies that to produce usable knowledge for sustainable development, researchers should know that (i) they are likely to be perceived as "taking sides" through the knowledge they choose to produce no matter what they do; (ii) the incentives they face in their choice of which questions to pursue are likely to disproportionately reflect the priorities of some interested parties and not others; and (iii) how they treat the knowledge of local stakeholders will either empower those stakeholders by helping to validate their knowledge claims or disempower them by conveying that such knowledge is of little value.

Decades of largely ineffective political negotiation over crafting global climate change agreements show both the contested nature of the science, as well as the interactions between science and politics. Taking the scientific understanding of climate change as a global earth system process into the political realm as a call for a global agreement has had profound ramifications for efforts to reduce carbon emissions (31). Commentators have pointed out that the scientific fact that climate change has global impacts does not necessarily mean that the best political path to action runs through global accords, especially when most of the world's emissions are produced by a small number of countries. Subglobal agencies were long disempowered as agents for mitigating climate change because the political discourse dictated that entrepreneurial local action should not be supported until there was a global accord. This blunder may be starting to change under the Paris Agreement on climate change with its emphasis on subnational actions. Nonetheless, political contestations over responsibilities and actions have brought the science of climate change into the political domain, with widely publicized challenges to the Intergovernmental Panel on Climate Change (IPCC). The small but vocal band of critics hasn't hesitated to accuse scientists who have built successful academic careers in climate research of pushing the climate agenda to further their own interests. Due to the inescapable political dimensions of the system in which researchers operate, debates over the truth or otherwise of these claims, or indeed of the science itself, have often been irrelevant to the main political claim of those few resisting action: that science should not hold any special position in political systems.

Researchers seeking to craft usable knowledge need to accept the political character of their work and to be aware that their science may impinge on power structures conditioning the opportunities of various actors. This means thinking through whose interests and agendas are likely to be supported, and whose threatened, by the problems we choose to address or ignore. It may mean forsaking research that academic colleagues would judge to be at the cutting edge of the field in favor of more mundane or practical work. It also means paying attention to the broader context, for example, where research projects generate positive outcomes at a local level (e.g., greater sex equity or minority empowerment) that are resented or counteracted by those further up the political hierarchy who are threatened by such outcomes.

Above all, researchers should know that they must earn the trust of potential users who may literally be risking their lives and livelihoods by acting on the new ideas, interventions, and devices that we push their way. Building such trust does, of course, require that our work be perceived as credible by users: that they see our new discoveries and insights as likely to be true and our new technologies as likely to perform as claimed. However, new knowledge must also be seen by users as salient (relevant) to their needs, rather than simply stuff that we ourselves are enthusiastic about. Finally, it must be seen to be legitimate: to have been created in ways that users see as "respectful of stakeholders' divergent values and beliefs, unbiased in its conduct, and fair in its treatment of opposing views and interests" $(32,33)$. How new knowledge can be crafted so that it will be perceived by users to meet these salience-credibility-legitimacy criteria, and thus be trusted enough to be used, is addressed in the next section of this paper.

\section{What Should Researchers Do About Usable Knowledge?} Understanding what makes knowledge usable for sustainable development is of limited value unless we also have the capacity to transform such understanding into practice. "Capacity," as we use the term here, includes the capability to act and the 
competence to do so effectively (34). We argue that to support the crafting of usable knowledge for sustainable development, researchers can and should help build core capacities for stakeholder collaboration, social learning, knowledge governance, and researcher training (Fig. 1).

Stakeholder Collaboration. Efforts to craft usable knowledge should build a capacity for collaboration with a wide and inclusive range of stakeholders in sustainable development (35). There are at least two reasons for this.

First, collaboration is needed because researchers can't craft usable knowledge on their own. Because our efforts involve dealing with complex systems, we need to collaborate with other experts-researchers and practitioners - who understand parts of the SES that we do not. Because our efforts to craft usable knowledge locate us in political systems, we need to collaborate with the intended users to craft a shared understanding of what sorts of knowledge, produced how, will be salient, credible and legitimate for them. Because our discoveries, insights and inventions are only part of the larger innovation system through which usable knowledge is created, we need to collaborate with evaluators and entrepreneurs who can help to nurture our research findings into action at larger scales. Finally, because we know these are also adaptive systems, we need to collaborate with people committed to long term monitoring and management who can help us design, assemble, and use feedback on how the SES responds to new knowledge interventions.

A second reason to build capacity for collaboration is that researchers shouldn't try to craft usable knowledge on their own. Understanding research as a social and political process, not just a process of discovery, highlights the moral and ethical dimensions of working with the people whose lives are affected by sustainability decisions. Building and using a capacity for collaboration is therefore both an important means for advancing inclusive development and an antidote to the elitism that expert-led development so often-and so inappropriately-entails. Researchers need to be aware, however, that the inclusion created through collaboration is never complete. Understanding the implications of knowledge for those who are "in" and those who are "out" must always remain an important aspect of the collaborative capacity that we seek to build.

How can researchers help build the capacity for collaboration that is needed to support the crafting of usable knowledge? First, researchers need to recognize that stakeholders are diverse. Meeting the needs of particular groups therefore requires tailored, often distinct, approaches to communication, engagement and building competencies within each group (35). Second, they need to appreciate that the opportunities for and barriers to collaboration among stakeholders are context specific. Strategies therefore need to be tailored to particular situations, acknowledging histories of conflict or cooperation (36). Third, researchers must grapple with the challenges of competing cultures (sets of assumptions, norms, incentives, and expectations) that can divide potential collaborators (37).

Bridging such cultural divides often benefits from "boundary work" $(38,39)$. Boundary work is essentially what its name implies: engagement at the interface among potential collaborators to address practical, political, and cultural mismatches in their notions of usable knowledge. It can be as simple as promoting communication among potential collaborators who have no history of talking with one another; or more complex, involving translation of mutually incomprehensible concepts. It can even involve mediation of substantive differences in goals or beliefs (32). Effective boundary work has been carried out informally by committed and respected individuals, and formally by dedicated organizations (e.g., agricultural extension services). The common feature of effective boundary workers is that they gain the trust of potential collaborators by working to promote the crafting of shared knowledge that is usable by all. The capacity for effective boundary work in a particular context can be difficult to build and hard to maintain. Because boundary workers are often looked on by the stakeholders they seek to bring together as neither classic researchers nor active users, their work is often undervalued. Researchers can contribute to capacity building for stakeholder collaboration by understanding the need for, and role of, boundary workers, by publically valuing their contributions, and by helping to protect them when their jobs or independence are threatened.

Social Learning. Researchers seeking to craft usable knowledge for sustainable development also need to build capacity for continuous, contextualized social learning. There are many definitions of social learning $(40,41)$. Here we focus on learning that takes place beyond the level of the individual: across teams and organizations. In such social learning, lessons, innovation, and change at higher levels of organization can be greater than the sum of individual experiences. This refocusing may often require substantial adjustments in present research capacities, oriented as they often are to the goals of knowing rather than learning (42).

The need for building learning capacities follows directly from the characteristics of SESs discussed earlier. Because such systems are complex, they will surprise us. Because they are adaptive, the rules that govern their behavior are continually changing in unpredictable ways. Because they are heterogeneous, those changes in rules will take different forms in different places. The prospects for accurately predicting the long term consequences of new ideas, policies, or technologies are thus limited $(43,44)$. We have no realistic choice but to treat the introduction of new knowledge as an experiment that presents us with opportunities to learn. In the previous section we argued that researchers need to engage in collaboration with a range of stakeholders; social learning is an important part of what those collaborations should do. Researchers can help build improved capacity for social learning in at least four key ways.

i) Individual researchers can adopt an orientation to their work that favors learning over knowing. Doing so implies a shift away from prevailing mental models that often represent research as individualistic, competitive and based on a search for science-based knowledge creation. Complementary models are also needed that see research as interactive, cooperative, and based on bringing multiple knowledges and expertise together. Social learning aims to create multidimensional, evolving understandings of complex issues.

ii) Organizations can design research arenas as "safe spaces" that reward rather than punish the recognition of error and failure. At their best, independent universities, think tanks, and the press have provided some of the most important safe spaces that are so central to social learning $(45,46)$. Researchers need to work to assure that the potential capacity of their own organizations for creating safe spaces is realized in practice.

iii) A third key area of capacity building for social learning is methodological. Research designs and methods are needed to facilitate the individual and organizational capacities noted above: methods for dialogue and knowledge sharing; research 
designs that establish baselines and allow for adaptation of the research as it progresses (47). Methodological innovations are needed that support learning within research projects, but also across the research community as experience and expertise in coproduction builds.

iv) Finally, fostering capacity for social learning means critically examining contemporary scientific institutions that favor single-issue, log-frame approaches to research while excluding diverse knowledges and iterative process. Extending the social learning community to include research funders and development agencies creates opportunities to reconsider markers of research quality and indicators of success. Building a dialogue with those responsible for evaluating research can start to address the structural constraints that hinder more widespread application of methods that better link research-based knowledge with action.

An emerging opportunity for social learning can be seen in current discussion and debates around the measurement of the UN Sustainable Development Goals (SDGs), with their renewed emphasis on data and monitoring (48). The so-called "data revolution" required by the SDGs is creating exciting new opportunities for rapidly expanding the global data pool on which social learning efforts can draw, both through facilitating formal monitoring systems via innovations in technologies, and through crowdsourcing. However, there is a large difference between designing elaborate monitoring systems and connecting these data to actual decision-making. Crafting such connections requires researchbased processes that foster collaboration, create safe spaces for experimentation, develop iterative methodologies, and engage evaluation communities in academia and the UN system. None of these experiments are likely to produce panacea solutions. However, many have latent in them valuable lessons that could inform efforts to shape a more effective learning system for the SDGs.

Knowledge Governance. Efforts to craft usable knowledge also need to build a capacity for recognizing and reshaping the rules and norms governing the relationships of coproduction. Knowledge governance is concerned with the formal and informal rules that govern knowledge processes, including production, sharing, access, and use (49). It includes familiar incentives such as promotion criteria and regulatory devices such as intellectual property law. However, it also encompasses less formal rules and norms that govern social expectations and judgments about how public decisions should be made. Building a capacity to understand prevailing systems of knowledge governance and to reshape them in the interests of sustainability is important for at least three reasons: (i) connecting knowledge across sites; (ii) scaling up research outcomes to larger programs or policies; and (iii) providing broader structural issues (50).

First, at a project scale, the assumptions and experiences we gain by learning to operate effectively within our own knowledge governance arrangements can create unrealistic and unsubstantiated assumptions about knowledge governance in different cultural or socio-political contexts. For example, the regular academic credentials such as recognized qualifications from respected institutions, peer-reviewed publications records, and project grant history may have little meaning or traction in contexts where knowledge becomes trusted through the personal connections, customary status, or local champions. Similarly, expectations such as transparency or objectivity in decision-making (both of which tend to facilitate the application of science) are not the same in all cultural settings. In other words, understanding knowledge governance can help us to better navigate what salience, credibility, and legitimacy actually mean in different socio-political contexts, as we conduct projects that take us beyond those places we are most familiar with.

Second, analyzing knowledge governance arrangements can help detect where, why, and how promising successes in particular projects or places can scale up to foster broader social change. When projects work because they have successfully changed the rules, norms, or values of those participating, we should remember that the original rules, norms, and values typically still hold sway outside the microcosm of the project. Understanding how knowledge processes work at a level beyond the project can help participants identify strategic ways to collaborate and build trust that will give the project reach outside its immediate team and setting.

Finally, at the broadest scale, recognizing the dynamics of knowledge governance can help researchers identify and advocate for rules that support the discoveries, inventions, and insights with a strong public good character that are so badly needed to advance sustainable development. Where prevailing rules favor knowledge production through private rather than public organizations, innovations for sustainability will continue to be disadvantaged and underproduced. For example, in early 2000s, researchers noted that of more than 1,000 new pharmaceutical entities registered between 1975 and 1999, barely 1\% were for tropical diseases or tuberculosis that together caused $11 \%$ of the global burden of disease. Private pharmaceutical companies simply did not find it profitable to research and develop such drugs $(51,52)$. Advocacy from public health researchers and practitioners led to the London Declaration of 2012, in which private companies agreed to provide resources requested by affected countries for drugs to tackle these "neglected" diseases. Awareness of the structural barriers that prevented both the creation of new knowledge (e.g., the need for profits) and the application of existing knowledge (e.g., lack of political pressure) together reconfigured the whole knowledge-to-action landscape with new public-private agreements. As this example shows, solutions can be integrated into the overall knowledge governance system in ways that address the bigger, more structural knowledge-to-action challenges, rather than "papering over" weaknesses through a few successful, but isolated, projects here and there.

Understanding the ways in which knowledge production and use are governed is our collective responsibility as researchers. Advocating for change where it is most needed offers practical strategies for connecting small-scale innovations to larger-scale structural change.

Researcher Training. Finally, a research community interested in promoting sustainable development should build capacity to extend its traditional training regimes. Needed are approaches that incorporate the additional skills and perspectives that will help to produce knowledge that is not only academically rigorous, but also usable and used in practice. Usable knowledge for sustainable development has long been produced by researchers in the absence of formal training, suggesting that informal and experiential approaches should not be underrated. Indeed, each of the authors of this paper, like many of the successful sustainability researchers we know, learned the craft of creating usable knowledge by muddling through in the field as much as by studying in the classroom. However, although learning the craft of producing usable knowledge, like learning any other craft, certainly benefits 
from on-the-job training and mentoring, these are not enough for the sustainability challenges that confront us. Bigger, better, and more inclusive formal training programs in the crafting of useable knowledge are also needed, covering (at least) the themes covered in this paper.

Many training models and modes are possible. We suggest that effective training should usually involve some mix of specially developed curriculum materials, innovative ways of integrating those materials into the existing training regimes of researchers, and internships in established programs that are effectively crafting usable knowledge for sustainable development. Collaboration with other stakeholders to address sustainability issues in the community, for instance, can be successfully integrated with learning experiences of students and academic development $(53,54)$. Several other relevant experiments in training scientists for crafting usable knowledge for sustainable development have already been launched and provide a rich trove of experience and approaches to draw on. These experiments range from the pioneering efforts of the International Center for Diarrheal Disease Research in Bangladesh (now icddr,b), to Sayer and Campbell's manual on The Science of Sustainable Development for natural resource managers striving to promote sustainable practices in the developing world (55), to the hundreds of academic programs now addressing sustainability issues. Each of the authors of this article has benefited through involvement in one or more such efforts.

A program to pool and analyze the lessons from these many training experiments might be a rewarding next step for the sustainability science community $(54,56)$. Practical curricula would also benefit from assembling or creating a number of rich case histories that document for a variety of contexts the trials, tribulations, surprises, and lessons of past efforts to craft usable knowledge. Some such histories already exist (57-59), but few have been incorporated into the normal training of young research scientists and engineers.

With regard to effective ways of teaching relevant curriculum materials, important unresolved issues remain, including when and how. One possibility is to introduce ideas on useable knowledge, and people who are expert in creating it, to graduate students as part of their normal training. Another option is to provide short courses later on at a time when young researchers begin their professional research careers and become more directly concerned with problems of moving from knowledge to action. Integrating material into existing courses taken by researchers as part of their current training may be most desirable, but harder to accomplish than creating stand-alone courses. Building capacity for researcher training might also benefit from opportunities for researchers to spend a period in user settings, ideally under the guidance of experienced mentors. More such internships linking active researchers with a wide range of business, civil society, and government decision makers around the world would surely raise our collective capacity to craft usable knowledge for sustainability. Again, a concerted effort to collect and assess the experiences of multiple experiments being conducted around the world in the when and how of usable knowledge training would almost certainly be worthwhile.

\section{Conclusion}

More usable knowledge is urgently needed to help meet the challenges of sustainable development. Some of that knowledge will continue to bubble up from the grassroots level through the entrepreneurship of local innovators with little or no formal research training (59). Some will continue to trickle down from the world's elite laboratories and universities through the work of classically trained scientists and engineers pursuing basic blue sky research (60). Some is being created by researchers who have chosen to target some or all of their work on use-inspired research in support of sustainability development (61). Important as these multiple sources of knowledge may be, however, they are inadequate for the task at hand. Harnessing the full potential of science and technology to promote sustainable development requires that more researchers target a significant portion of their efforts on sustainability problems, and that those efforts become more effective in producing knowledge that is truly useful_and used_for achieving sustainability goals. We believe that these two requirements are related. Many researchers we know would be willing to focus more of their work on sustainability problems if they believed that doing so would actually help, in the framing of Amartya Sen, to "inform agitation" on the front lines of action for sustainable development (62).

We argued in this paper that there is a learnable skill to crafting usable knowledge for sustainable development. Relevant lessons have emerged from a combination of field experience and scholarly study over the last several decades, but are not generally included in the training of professional researchers. We attempted to distill here the most important of those lessons and to present them in a form accessible to researchers who want to do a better job in harnessing their knowledge and skills to promote sustainable development. In essence, we argue that researchers seeking to craft more useable knowledge for sustainable development should know (at least) four things and do (at least) four things. The knowing involves understanding the idea of coproduction: that knowledge making and decision making are continuously reshaping one another in the SESs that constitute the stage on which the drama of sustainable development is played out. We highlighted lessons for the crafting of usable knowledge that emerge from examining coproduction from the perspectives of SESs seen as innovation systems, complex systems, adaptive systems, and political systems. The doing involved in crafting usable knowledge for sustainable development constitutes efforts that improve the capacity of the research community to put its understanding of coproduction into practice. We highlight steps through which researchers can help build capacities for stakeholder collaboration, social learning, knowledge governance, and researcher training.

We suggested some of the myriad institutional reforms that could and should be carried out to support the crafting of more usable knowledge for sustainable development. However, we also believe that individual researchers have both a responsibility and multiple opportunities to contribute. In that spirit, we hope the ideas presented here will help and encourage our readers to contribute to existing efforts that are pursuing sustainability in real-world complex systems; to support others currently engaged in such work; to share lessons learnt as a peer or teacher; to reflect critically on their own experiences and the insights shared by others; and to use the resulting lessons_enthusiastically but humbly_as a guide to improve the crafting of usable knowledge for sustainable development.

\section{Acknowledgments}

This work was supported by the National Oceanic and Atmospheric Administration's Climate Program Office, National Science Foundation Award SES-0621004; the Italian Ministry for Environment, Land, and Sea through its support of the Sustainability Science Program at Harvard University; and the International Development Research Centre, Ottawa, support to research on climate and water by the Unit for Social and Environmental Research at Chiang Mai University. 
1 Dasgupta PS (2013) The nature of economic development and the economic development of nature. Econ Polit Wkly 48(51):39-51.

2 Polasky S, et al. (2015) Inclusive wealth as a metric of sustainable development. Annu Rev Environ Resour 40:445-466.

3 UNDP (2011) Sustainability and Equity: A Better Future for All: Human Development Report 2011 (United Nations Development Program, New York).

4 Fazey I, et al. (2014) Evaluating knowledge exchange in interdisciplinary and multi-stakeholder research. Glob Environ Change 25:204-220.

5 Kirchhoff CJ, Lemos MC, Dessai S (2013) Actionable knowledge for environmental decision making: Broadening the usability of climate science. Annu Rev Environ Resour 38:393-414.

6 Eakin H, Luers LA (2006) Assessing the vulnerability of social-environmental systems. Annu Rev Environ Resour 31:365-394.

7 Ostrom E (2009) A general framework for analyzing sustainability of social-ecological systems. Science 325(5939):419-422.

$8 \mathrm{Liu}$ J, et al. (2015) Sustainability. Systems integration for global sustainability. Science 347(6225):1258832.

9 Jasanoff S (2004) States of Knowledge: The Co-Production of Science and the Social Order (Routledge, London).

10 Reyers B, Nel JL, O'Farrell PJ, Sitas N, Nel DC (2015) Navigating complexity through knowledge coproduction: Mainstreaming ecosystem services into disaster risk reduction. Proc Natl Acad Sci USA 112(24):7362-7368.

11 Brooks H (1980) Technology, evolution, and purpose. Daedalus 109(1):65-81.

12 Fagerberg J, Mowery D, Nelson R (2005) The Oxford Handbook of Innovation (Oxford Univ Press, Oxford, UK).

13 Geels FW (2005) Processes and patterns in transitions and system innovations: refining the co-evolutionary multi-level perspective. Technol Forecast Soc Change 72(6):681-696.

14 Anadon LD, et al. (2015) Making technological innovation work for sustainable development. Harvard Kennedy School Faculty Research Working Paper Series RWP15-079 (Harvard Kennedy School, Cambridge, MA).

15 Pingali PL (2012) Green revolution: Impacts, limits, and the path ahead. Proc Natl Acad Sci USA 109(31):12302-12308.

16 Kesavan PC, Swaminathan MS (2008) Strategies and models for agricultural sustainability in developing Asian countries. Philos Trans R Soc Lond B Biol Sci 363(1492):877-891.

17 Norberg J, Cumming GS, eds (2008) Complexity Theory for a Sustainable Future (Columbia Univ Press, New York).

18 Ostrom E, Janssen MA, Anderies JM (2007) Going beyond panaceas. Proc Natl Acad Sci USA 104(39):15176-15178.

19 Naylor R, et al. (2007) The ripple effect: Biofuels, food security, and the environment. Environment 49(9):31-43.

20 Hertel TW, et al. (2010) Effects of US maize ethanol on global land use and greenhouse gas emissions: Estimating market-mediated responses. Bioscience 60(3):223-231.

21 Headey D, Fan S (2010) Reflections on the global food crisis: How it happened? How it hurt? And, how we can prevent the next one? IFPRI Research Monograph (International Food Policy Research Institute, Washington, DC), Vol 165, p 1-142.

22 Matson P, Clark W, Andersson K (2016) Pursuing Sustainability: A Guide to the Science and Practice (Princeton Univ Press, Princeton).

23 Jasanoff S (2003) Technologies of humility: Citizen participation in governing science. Minerva 41(3):223-244.

24 Levin S, et al. (2013) Social-ecological systems as complex adaptive systems: Modeling and policy implications. Environ Dev Econ 18(02):111-132.

25 Miller JH, Page SE (2007) Complex Adaptive Systems: An Introduction to Computational Models of Social Life (Princeton Univ Press, Princeton).

26 Webb J (2009) Humanity's Burden: A Global History of Malaria (Cambridge Univ Press, New York).

27 Keusch GT, Kilama WL, Moon S, Szlezák NA, Michaud CM (2010) The global health system: linking knowledge with action-Learning from malaria. PLoS Med 7(1): e1000179.

28 Berkhout F, et al. (2010) Sustainability experiments in Asia: Niches influencing alternative development pathways? Environ Sci Policy 13(4):261-271.

29 Hilgartner S, Miller C, Hagendijk R (2015) Science and Democracy: Making Knowledge and Making Power in the Biosciences and Beyond (Routledge, New York).

30 Jasanoff S (2006) States of Knowledge: The Coproduction of Science and Social Order (Routledge, London).

31 Bulkeley H, Newell P (2010) Governing Climate Change (Routledge, New York).

32 Cash DW, et al. (2003) Knowledge systems for sustainable development. Proc Natl Acad Sci USA 100(14):8086-8091.

33 Posner SM, McKenzie E, Ricketts TH (2016) Policy impacts of ecosystem services knowledge. Proc Natl Acad Sci USA 113(7):1760-1765.

34 van Kerkhoff LE, Lebel L (2015) Coproductive capacities: Rethinking science-governance relations in a diverse world. Ecol Soc 20(1):14.

35 Meadow AM, et al. (2015) Moving toward the deliberate coproduction of climate science knowledge. Weather Clim Soc 7(2):179-191.

36 Foster-Fishman PG, Berkowitz SL, Lounsbury DW, Jacobson S, Allen NA (2001) Building collaborative capacity in community coalitions: A review and integrative framework. Am J Community Psychol 29(2):241-261.

37 Aas C, Ladkin A, Fletcher J (2005) Stakeholder collaboration and heritage management. Ann Tour Res 32(1):28-48.

38 Knight AT, et al. (2006) Designing systematic conservation assessments that promote effective implementation: Best practice from South Africa. Conserv Biol 20(3):739-750.

39 Clark WC, et al. (2011) Boundary work for sustainable development: Natural resource management at the Consultative Group on International Agricultural Research (CGIAR). Proc Natl Acad Sci USA 113:4615-4622.

40 Reed MS, et al. (2010) What is social learning? Ecol Soc 15(4):r1.

41 Siebenhüner B, Rodela R, Ecker F (2016) Social learning research in ecological economics: A survey. Environ Sci Policy 55(Part 1):116-126.

42 Social Learning Group (2001) Learning to Manage Global Environmental Risks: A Comparative History of Social Responses to Climate Change, Ozone Depletion and Acid Rain (MIT Press, Cambridge, MA).

43 Morgan MG, Keith D (2008) Improving the way we think about projecting future energy use and emissions of carbon dioxide. Clim Change 90(3):189-215.

44 Pindyck RS (2013) Climate change policy: What do the models tell us? J Econ Lit 51(3):860-872.

45 Reid RS, et al. (2009) Evolution of models to support community and policy action with science: Balancing pastoral livelihoods and wildlife conservation in savannas of East Africa. Proc Natl Acad Sci USA 113:4579-4584.

46 Kristjanson P, et al. (2009) Linking international agricultural research knowledge with action for sustainable development. Proc Natl Acad Sci USA 106(13): 5047-5052.

47 Russell AW, Wickson F, Carew AL (2008) Transdisciplinarity: Context, contradictions and capacity. Futures 40(5):460-472.

48 Selomane O, Reyers B, Biggs R, Tallis H, Polasky S (2015) Towards integrated social-ecological sustainability indicators: Exploring the contribution and gaps in existing global data. Ecol Econ 118:140-146.

49 van Kerkhoff L (2014) Knowledge governance for sustainable development: A review. Challenges Sustain 1(2):82-93.

$\mathbf{5 0}$ van Kerkhoff L, Lebel L (2006) Linking knowledge and action for sustainable development. Annu Rev Environ Resour 31:445-477.

51 The Lancet (2014) Neglected tropical diseases: Becoming less neglected. Lancet 383(9925):1269.

52 Trouiller P, et al. (2002) Drug development for neglected diseases: A deficient market and a public-health policy failure. Lancet 359(9324):2188-2194.

53 Trencher G, Terada T, Yarime M (2015) Student participation in the co-creation of knowledge and social experiments for advancing sustainability: Experiences from the University of Tokyo. Curr Opin Environ Sustain 16:56-63.

54 Yarime M, et al. (2012) Establishing sustainability science in higher education institutions: Towards an integration of academic development, institutionalization, and stakeholder collaborations. Sustain Sci 7(suppl 1):101-113.

55 Sayer J, Campbell B (2004) The Science of Sustainable Development: Local Livelihoods and the Global Environment (Cambridge Univ Press, Cambridge, UK).

56 Wiek A, Withycombe L, Redman C (2011) Key competencies in sustainability: A reference framework for academic program development. Sustain Sci 6(2): $203-218$. 
57 Lee KN (1992) Compass and Gyroscope: Integrating Science and Politics for the Environment (Island Press, Washington, DC). 58 Matson P, ed (2012) Seeds of Sustainablility: Lessons From the Birthplace of the Green Revolution (Island Press, Washington, DC).

59 Gupta AK (2013) Tapping the entrepreneurial potential of grassroots innovation. Stanford Social Innovation Rev 11(3):18-20.

60 Conway G, Waage J (2010) Science and Innovation for Development (UK Collaborative on Development Sciences, London).

61 Kates RW (2011) What kind of a science is sustainability science? Proc Natl Acad Sci USA 108(49):19449-19450.

62 Sen A (2013) The ends and means of sustainability. J Human Dev Capabil 14(1):6-20. 